\title{
Tratamento fisioterapêutico de pubalgia em atleta de futsal profissional: estudo de caso
}

\author{
Physioterapeutic treatment of pubalgy in a \\ professional athlete of futsal: case study
}

FisiSenectus. Unochapecó Ano 1 - Edição especial - 2013 p. $48-53$

\section{Júlia Raqueli da Silva}

Acadêmica do curso de graduação de Fisioterapia da Universidade Comunitária da Região de Chapecó, julia_rs@unochapeco.edu.br

\section{Ketryn Danieli Frank}

Acadêmica do curso de graduação de Fisioterapia da Universidade Comunitária da Região de Chapecó, ketryn@unochapeco.edu.br

\section{Márcia Regina da Silva}

Docente da Universidade Comunitária da Região de Chapecó, marciaf@unochapeco.edu.br

\section{Resumo}

Introdução: A pubalgia é descrita, do ponto de vista fisiopatológico, como um processo inflamatório que acomete a sínfise púbica, produzindo alterações condrais e ósseas nesta articulação. Calcula-se que $5 \%$ de todas as lesões no futebol ocorrem na região do púbis e virilha. Objetivos: 0 objetivo do presente estudo é identificar quais os resultados da fisioterapia no atleta de futsal com história de lesão em adutor e diagnóstico de pubalgia. Materiais e métodos: 0 estudo de caso foi realizado com um jogador de futsal profissional com 17 anos, atuante na posição de pivô. 0 atleta foi avaliado e as intervenções foram realizadas nas dependências do laboratório de Fisioterapia da Universidade Comunitária da Região de Chapecó (Unochapecó). As sessões foram baseadas em exercícios de alongamento e fortalecimento muscular, realizadas uma vez por semana, não consecutivas. Resultados: Na reavaliação o jogador apresentou ganho de amplitude de movimento em adução e abdução do quadril, aumento da flexibilidade muscular em adutores, abdutores, isquiotibiais e quadríceps e diminuição do quadro álgico em região pélvica e adutor de membro inferior esquerdo. Conclusão: Conclui-se que o tratamento realizado no atleta foi capaz de aumentar a flexibilidade, amplitude de movimento e diminuir a dor na região do púbis.

\section{Palavras-chave}

Desportiva. Lesão. Sínfise púbica. 


\begin{abstract}
Introduction: The pubalgia is described, pathophysiological point of view, as an inflammatory process that affects the pubic symphysis, producing contras and bone changes in this joint. It is estimated that $5 \%$ of all football injuries occur in the region of the pubis and groin. Objective: The objective of the present study is to identify what the results of physiotherapy in futsal athlete with a history of adductor injury and diagnosis of pubalgia. Materials and Methods: The case study was conducted with a professional futsal player with 17 years, active in the pivot position. The athlete was evaluated and the interventions were carried out in the facilities of the laboratory of physiotherapy, Community University in Chapecó -Unochapeco. The sessions were based on muscle strengthening and stretching exercises, performed once a week, not consecutive. Results: At reassessment, the player showed gain range of motion in hip abduction and adduction, abductors and adductors muscle flexibility, hamstrings and quadriceps and decrease pain in the pelvic area and left lower limb adductor. Conclusion: It is concluded that the treatment performed at the athlete was able to increase flexibility, range of motion and decrease pain in the pubic region.
\end{abstract}

\title{
Keywords
}

Sports. Lesion. Pubic symphysis.

\section{Introdução}

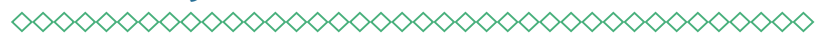

A pubalgia é uma inflamação que ocorre na região do osso do púbis, ponto de origem-inserção de diversos músculos, como adutores da coxa (longo, curto, magno e pectíneo), localizados na porção inferior e os abdominais na superior. As tensões exageradas das estruturas músculo-tendíneas decorrem comumente da prática de alguns esportes, tais como futebol, rugby e corridas de longa distância (maratonas) e tênis ${ }^{1}$.

A sínfise púbica é uma articulação do tipo anfiartrose, com fina camada de cartilagem hialina, separada por um disco de fibrocartilagem. 0 movimento nesta articulação é muito limitado, sendo estabilizado superiormente pelo ligamento suprapúbico, inferiormente pela porção arcada do ligamento púbico e anteriormente pelo ligamento interpúbico².

A pubalgia é descrita, do ponto de vista fisiopatológico, como um processo inflamatório que acomete a sínfise púbica, produzindo alterações condrais e ósseas nesta articulação².

O futebol é um dos esportes mais populares do mundo, sendo praticado por mais de 240 milhões de pessoas em mais de 186 países, com praticantes em todas as faixas etárias e em diferentes níveis; destes, 30 milhões encontram-se no Brasil ${ }^{3}$. O futebol é responsável pelo maior número de lesões desportivas do mundo, sendo responsável por 50 a $60 \%$ das lesões esportivas na Europa e por até $10 \%$ dos traumas físicos ${ }^{4}$.

A pubalgia dentro do futebol se tem caracterizado como um problema grave e crescente, preocupando atletas, treinadores, médicos e fisioterapeutas. 0 aumento de sua incidência é inegável, sendo justificado por algumas hipóteses: aumento da magnitude e dos valores a serem atingidos pelos atletas, o aumento da carga e do volume de treinamento, inovações no treinamento da técnica e tática, baixa preparação técnica dos treinadores $^{5}$. Calcula-se que $5 \%$ de todas as lesões no futebol ocorrem na região do púbis e virilha ${ }^{6}$.

0 tratamento é variado e contraditório, mas o conservador é sempre indicado em um primeiro momento. Repouso e o uso de anti-inflamatórios esteroides e não esteroides são recomendados; nos casos de infecção antibióticos também estão indicados ${ }^{2}$.

A realização de fisioterapia analgésica, seguido de fortalecimento e alongamento da musculatura abdominal e adutora, também estão indicados durante a fase de tratamento conservador ${ }^{7}$.

A partir do pressuposto, o presente estudo visa identificar quais os resultados da fisioterapia no atleta de futsal com história de lesão em adutor e diagnóstico de pubalgia. 


\section{Apresentação do caso}

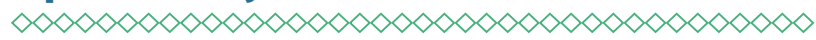

A pesquisa constou do estudo de caso de um jogador de futebol profissional com 17 anos, praticante do esporte desde os seis anos, atuante na posição de pivô, possui história de lesão em adutor e diagnóstico clínico de pubalgia. 0 estudo foi realizado nas dependências do laboratório de Fisioterapia da Universidade Comunitária da Região de Chapecó (Unochapecó). No primeiro momento foi realizada a avaliação baseada na Ficha de Avaliação Fisioterapêutica para a Disciplina de Fisioterapia Desportiva da Unochapecó, composta de anamnese para obtenção de informações referentes ao quadro clínico e exame físico com inspeção, palpação, medida da amplitude de movimento muscular, mensuração dos membros inferiores, avaliação de retração muscular, força muscular, trofismo e análise postural.

Foram enfatizadas as seguintes variáveis: a avaliação da flexibilidade articular de MMII através no Manual de Goniometria segundo Marques ${ }^{8}$, com foco em adutores e abdutores, já a força muscular dos abdutores e adutores de quadril, quadríceps, íliopsoas, isquiotibiais e abdominais foram avaliados seguindo os critérios de classificação da Escala de Kendall ${ }^{9}$, os testes de retrações musculares de íliopsoas, quadríceps, isquiotibiais e tríceps sural segundo Magee $^{10}$ e a sintomatologia de dor na região pélvica através de testes especiais como o teste de Grava ${ }^{11}$ e Lacuna da Sínfise ${ }^{12}$.

0 tratamento fisioterapêutico foi desenvolvido através dos resultados obtidos durante a avaliação. Foram realizadas cinco intervenções durante cinco semanas não consecutivas, com frequência de uma sessão semanal e uma hora de duração. Ao final de todas as semanas foi realizada a reavaliação com o indivíduo para acompanhar os resultados obtidos através das intervenções. Os critérios para a reavaliação foram os mesmos utilizados na avaliação.

Inicialmente foi realizado o teste especial de Manobra de Grava, usada para testar a instabilidade da sínfise púbica, o desequilíbrio da musculatura adutora e reto abdominal. No teste o paciente posicionou-se em decúbito dorsal com uma perna em abdução e flexão de setenta graus, o terapeuta forçou a abertura e pediu ao paciente que fizesse abdominais, se a dor não permitisse o movimento a manobra seria considerada positiva. Como coadjuvante foi realizado o teste de Lacuna da Sínfise onde o atleta permaneceu em decúbito dorsal, com flexão de quadril e joelho a noventa graus, com as pernas apoiadas pelo examinador. 0 atleta então executou uma contração isométrica dos músculos adutores contra o punho do examinador, a resposta dolorosa do músculo caracterizava o teste como positivo.

A partir da avaliação e dos testes especiais percebeu-se retração de isquiotibiais e quadríceps, em que o princípio do tratamento para diminuir a retração destes grupos musculares foram os seguintes exercícios:

Foi realizado alongamento ativo para a cadeia anterior com exercício postura rã no chão segundo Souchard ${ }^{13}$, em que o atleta permaneceu em decúbito dorsal, membros inferiores com quadris em flexão, abdução e rotação externa, joelhos flexionados, tornozelos plantifletidos e pés tocando um ao outro em inversão; membros superiores em posição anatômica. 0 atleta evoluía na postura estendendo os quadris e joelhos e abduzindo os ombros, mantendo os cotovelos estendidos, punhos neutros e dedos estendidos. Foi realizado alongamento passivo de isquiotibiais e tríceps sural, em decúbito dorsal, membros superiores ao longo do corpo, o fisioterapeuta com uma das mãos estabiliza a articulação do joelho e com a outra realiza dorsiflexão de tornozelo e flexão de quadril. Para o autoalongamento da musculatura de quadríceps, o atleta permaneceu em decúbito ventral, quadril neutro e joelhos em flexão segurando uma faixa elástica envolta na articulação subtalar, aproximando a articulação dos glúteos.

Para o tratamento da sintomatologia da pubalgia e lesão em adutor foram elencados exercícios como alongamento para adutores de quadril com atleta sobre a bola suíça, quadris levemente abduzidos e pés apoiados no solo, deslizando a bola para um dos lados, flexionando um dos joelhos, e o outro joelho deverá ficar em extensão. Para trabalhar especificamente com adutor curto foi realizado o alongamento com o atleta sentado, quadris abduzidos e rodados externamente, joeIhos flexionados e a planta dos pés unidas impul- 
sionando os joelhos na direção do solo até o seu limite de amplitude, em seguida foram colocadas as mãos na parte medial dos joelhos para oferecer resistência a contração isométrica de adutores durante seis segundos, relaxando, e em seguida aprofundando o alongamento.

Para adutor longo o atleta permaneceu em supino com os joelhos estendidos, os quadris eram abduzidos sem promover rotação (afastando os membros o máximo que conseguisse), em seguida oferecia-se resistência à contração isométrica durante seis segundos e, após, era aprofundado o alongamento dos adutores.

Foi realizado fortalecimento de adutores de quadril com o atleta sentado sobre a bola suíça com uma bola pequena entre os MMII logo acima da articulação dos joelhos, solicitando que o atleta aperte a bola o máximo que conseguisse, tentando manter a contração por cinco segundos relaxando em seguida.

Foi realizado alongamento e fortalecimento da musculatura envolvida no core, que, de acordo com Greve ${ }^{11}$, é definido como sendo o complexo lombar-pélvico localizado nos quadris, o exato lugar do centro de gravidade do corpo, ponto que se desenvolve o início de todos os movimentos. Os principais músculos do complexo são os músculos da coluna vertebral, abdominais, iliopsoas, glúteos, isquiotibiais, rotadores externos do quadril. Para este fim, os exercícios selecionados foram de ponte bipodal, unipodal, lateral e posterior.

No exercício de ponte bipodal o paciente permaneceu em decúbito dorsal, MMSS ao longo do corpo apoiados no solo, quadris e joelhos fletidos e pés apoiados no solo, pedia-se que o paciente estendesse os quadris (elevando a pelve), joelho a $90^{\circ}$, pés neutros posicionados sobre a maca, mantendo a posição por 30 segundos.

Para o exercício de ponte unipodal o paciente iniciava em decúbito dorsal, na mesma posição anterior, pedia-se que o mesmo estendesse os quadris e em seguida estendesse um joelho mantendo o tornozelo em dorsiflexão, o outro membro com joelho a $90^{\circ}$, pé neutro posicionado sobre a maca, mantendo a posição por 30 segundos. Exercício de ponte lateral, paciente em decúbito lateral, ombros abduzido, cotovelo fletido e com o antebraço pronado apoiado no chão, elevava o corpo do solo mantendo o cotovelo em flexão e o ombro em abdução, mantendo o alinhamento da cabeça e da pelve. MMII com pés posicionados um a frente do outro, permitindo que os dois tocassem o solo. Solicitava-se a contração do abdome e manutenção da postura por 30 segundos.

O exercício de ponte posterior foi realizado com o paciente em decúbito ventral, ombros e cotovelos fletidos a $90^{\circ}$, antebraços pronados e apoiados ao chão, em seguida solicitava para alinhar a coluna na posição neutra elevando pelve, abdome e joelhos do solo, fazendo extensão do quadril de um MI, deixando apenas a ponta de um dos pés no solo. A postura era mantida por 30 segundos.

\section{Resultados e discussão}

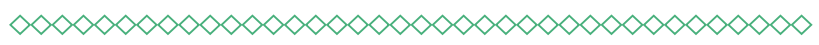

A sínfise púbica, embora revestida, em grande parte, pelos músculos da virilha e abdome, é constituída apenas pelo periósteo e fáscia parietal. Essa área da sínfise é particularmente suscetível às forças de cisalhamento durante determinadas atividades atléticas, como a corrida, o salto e o chute. Nesse momento, a sínfise movimenta-se para cima e para baixo, chegando a rodar levemente, o que facilita o microtrauma. Como é pequeno o suprimento sanguíneo nessa área, ela não está muito bem preparada para suportar esse estresse, podendo desenvolver uma inflamação aguda chamada de osteíte púbica ${ }^{14}$.

Aparece como consequência de uma agressão na sínfise pubiana, como consequência de uma queda sobre os pés, em que as forças do chão podem ser desiguais. Um ramo púbico pode elevar-se mais que o outro causando um cisalhamento do púbis com estiramentos dos ligamentos púbicos, associado a um bloqueio do ramo púbico superior. Outra consequência pode ser a perda do apoio no chão em movimento contrário a extremidade inferior, que provocará uma tensão súbita nos adutores. Este estresse pode deteriorar os ligamentos ou as inserções musculares que se localizam no púbis. Essa lesão pode ser completada por uma tração para baixo do ramo pubiano, que se bloqueia em inferioridade ${ }^{15}$

Na avaliação da sintomatologia da pubalgia através dos testes de Grava e Lacuna da Sínfise 
na primeira avaliação o atleta referiu dor, restringindo o movimento durante o teste, que obteve resultado positivo. Após as intervenções, na reavaliação foram realizados novamente os testes, onde o atleta apresentou considerável diminuição do quadro álgico, sem impedimento na realização do movimento durante o teste. Apresentou apenas sintomas álgicos leves pós-teste, na fase de relaxamento, referindo dor na região da musculatura adutora do membro inferior esquerdo.

No goniometria foram a enfatizados os movimentos de adução e abdução os quais eram mais restringidos devido ao quadro álgico. Na primeira avaliação no movimento de hiperadução do membro inferior esquerdo teve como resultado $0^{\circ}-13^{\circ}$ e no membro inferior direito teve como resultado $0^{\circ}-15^{\circ}$ de amplitude de movimento.

No movimento de abdução tanto no membro inferior esquerdo quanto no direito teve como resultado $0^{\circ}-20^{\circ}$ de amplitude de movimento. Após as cinco intervenções na reavaliação observou-se uma melhora no movimento de hiperadução do membro inferior esquerdo, este passando de $0^{\circ}-13^{\circ}$ para $0^{\circ}-15^{\circ}$ de amplitude de movimento. No movimento de abdução do membro inferior esquerdo também se observou melhora passando de $0^{\circ}-20^{\circ}$ para $0^{\circ}-30^{\circ}$ de amplitude de movimento.

Nos testes elencados para avaliação da retração muscular o atleta apresentou os seguintes resultados: grupo muscular de quadríceps e isquiotibiais positivo, íliopsoas e tríceps surais negativos. Na reavaliação pela avaliação subjetiva houve diminuição da retração muscular de quadríceps passando a apresentar resultado negativo no teste de retração.

Na avaliação de força muscular, para os músculos abdutores e adutores de quadril, quadríceps, íliopsoas, isquiotibiais, foi notado grau 5 de força muscular segundo a escala de Kendall ${ }^{9}$, que se manteve até o final da intervenção fisioterapêutica. Para os abdominais na avaliação inicial, o jogador apresentou grau de força muscular classificado em grau 5 na escala de Kendall ${ }^{9}$, permanecendo com este valor até a reavaliação.

\section{Conclusão}

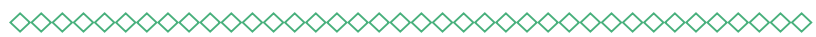

Os resultados apresentados pelo atleta em questão demonstraram que o tratamento da fisioterapia ofereceu ganho de amplitude de movimento para adução e abdução do membro inferior esquerdo, diminuição da sintomatologia da pubalgia, e melhora na flexibilidade muscular de quadríceps, isquiotibiais, adutores e abdutores, não apresentou aumento considerável de forca muscular em abdominais. Acredita-se que não foi possível observar maiores ganhos devido ao curto tempo de intervenções e a frequência das mesmas não ter ocorrido de forma continua.

\section{Referências}

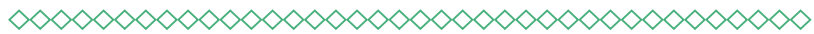

1. Montes GA. Relación entre lá condición física i su incidência em grupos de alto riesgo. Rev. Int. Med. Cienc. Act. Fis. Desporte. 2002;32(6):22-5.

2. Azevedo E, Dani, WS. Elementos básicos de diagnóstico e de terapêutica da pubalgia. Temas De Reumatologia Clínica. 2007;8(3):68-70.

3. Ribeiro RN, Vilaça F, Oliveira HU, Vieira LS, Silva AA. Prevalência de lesões no futebol em atletas jovens: estudo comparativo entre diferentes categorias. Rev Bras Educ Fis Esporte. 2007;21(3):189-94.

4. Keller CS, Noyes FR, Bunche CR. The medical aspects of soccer injury epidemiology. Am J Sports Med. 1987;15(1):105-12.

5. Po F, Vannucci C, Bianco M, Calvosa G. La pubalgia da sport. Ital J Sports Traumatology. 1989;11:47-55.

6. Taylor DC, Meyers WC, Moylan JA, Lohnes J, Basset FH, Garrett WE. Abdominal musculature abnormalities as a cause of groin pain in athletes. Am J Sports Med. 1991;19(3):239-42.

7. Sousa JPG, Fallopa F, Siqueira Jr D, Santa Cruz, ARS: Tratamento cirúrgico da pubalgia em jogadores de futebol profissional. Rev Bras Ortop. 2005;40(10):601-7. 
8. Marques, AP. Manual de goniometria. 2a ed. São Paulo: Manole; 2003.

9. Kendall, FP, Mccreary, EK, Provance, PG. Músculos provas e funções. 4a ed. São Paulo: Manole; 1995.

10. Magee, DJ. Avaliação musculoesquelética. 3a ed. São Paulo: Manole; 2002.

11. Greve, JMA. Tratado de medicina de reabilitação. 1a ed. São Paulo: Roca; 2007.

12. Rodriguez C, Miguel A, Lima H, Heinrichs

K. Osteitis púbis syndrome in the profissional soccer athlete: a casa report. Jornal Athl. Train. 2001;36(4):337-440.

13. Souchard, PE. Reeducação Postural Global: método de campo fechado. 5a ed. São Paulo: Ícone; 2004.

14. Mellion, MB. Segredos em medicina desportiva. Porto Alegre: Artes médicas; 1997.

15. Busquet, L. As Cadeias Musculares: A Pubalgia. São Paulo: Edições Busquet; 2001. 